\title{
Cancer Immunotherapy Arsenal: Current and Promising New Approaches
}

\author{
Veerendra Koppolu ${ }^{1 *}$ and Veneela KR Vasigala ${ }^{2}$ \\ ${ }^{1}$ Department of Molecular Biosciences, University of Kansas, USA \\ ${ }^{2}$ Rangaraya Medical College, NTR University of Health Sciences, India
}

Submission: May 10, 2017; Published: June 08, 2017

"Correspondence Address: Veerendra Koppolu, Department of Molecular Biosciences, University of Kansas, Lawrence, KS, USA-66047, Tel: +1 6786979216; Email: veeru.bios@gmail.com

\begin{abstract}
The remarkable specificity of the immune cells to antigens has long drawn the attention of immunologists and oncologists to develop immunotherapies to fight cancer. Recent developments in detailed understanding of the biology of tumor/host immune responses have considerably increased our attention in exploring immunotherapeutic treatment approaches. Two major strategies that are getting clinical validation are, targeting immunosuppression pathways in the tumor microenvironment, and raising the overall tumor antigen specific cytotoxic $\mathrm{T}$ cell populations to tilt the balance towards immune specific tumor control.

Relieving the negative signaling pathways (immunosuppression) of $\mathrm{T}$ cell activation using antibodies to immune checkpoints such as cytotoxic T lymphocyte antigen (CTLA-4) and programmed death-1 (PD-1)/ programmed death ligand-1 (PDL-1) have emerged as an attractive strategy and are now approved by FDA for treating patients suffering from various cancers. Recently, adoptive T cell therapy using chimeric antigen receptor (CAR) T cells has shown a great promise in clinical trials and is being actively pursued to treat cancers by in vitro rising of T cells. In the context of these advances, active immunotherapy either alone or in combination with other tumor targeted approaches are considered as promising ways to unleash a long-lasting and durable responses to cancer.
\end{abstract}

Keywords: Cancer Immunotherapy; CTLA-4; PD-1; PDL-1; Immunosupression; CAR T cell therapy; Adaptive Immune Therapy; Ipilimumab; Nivolumab

Abbreviations: CTLA-4: Cytotoxic T Lymphocyte Antigen-4; PD-1: Programmed Death; APC: Antigen Presenting Cells; NSCLC: Non-Small Cell Lung Cancer; IgG1: Immunoglobulin G; ALL: Acute Lymphoblastic Leukemia

\section{Introduction}

Cancer immunotherapy is an approach of treating cancer by harnessing the body's own immune system potential to fight cancer and differs from chemotherapeutic strategies that target tumor itself. Cancer immunotherapy has gained momentum as multiple evidences suggest the role of immune system in fighting the cancer. Some of the evidences include, presence of tumor specific $\mathrm{T}$ lymphocytes in the tumor microenvironment and tumor draining lymph nodes, existence of tumor infiltrating immune cells including lymphocytes and monocytes, increasing cases of cancer in immunosuppressed patients, and evidence of cancer remission with immune modulators.

Increasing availability of tools to understand the biology of tumors/host immune system interactions is providing immunotherapy with more ways to utilize immune system to treat cancers. Although much complicated, the development of endogenous immune responses to cancer will follow some key steps which are explored in immunotherapy [1]. Briefly, tumor specific antigens (for example mutated proteins expressed in cancers, non-mutated proteins preferentially expressed in cancers, differential antigens associated with cancer tissue of origin, and antigens against which thymic immune tolerance is not achieved) released either spontaneously or from dead or necrotic cancer cells during the process of oncogenesis will be taken by dendritic cells leading to their activation/maturation.

The activated dendritic cells present the antigens on the surface of their membrane bound MHC receptors and travel to lymph nodes where they prime the $\mathrm{T}$ cells leading to differentiation into tumor antigen specific effector $\mathrm{T}$ cells with cytotoxic potential. The priming step involves a primary interaction of $\mathrm{T}$ cell receptors with antigen expressed on MHC, and a co-stimulatory interactions of CD28 of T cells and B7 class 
of molecules (B7.1 and B7.2) on dendritic cells [2]. Although, T cells can interact with tumor antigens directly, it may not activate $\mathrm{T}$ cells because of down regulation of $\mathrm{B} 7$ class of molecules on tumor cells limiting the co-stimulation required for $\mathrm{T}$ cell activation.

The differentiated $\mathrm{T}$ cells travel through blood vessels, infiltrate the tumor microenvironment, and specifically kill tumor cells [3-5]. Tumors are shown to counter host immune responses either by skewing dendritic cell maturation or initiating immune suppressive mechanisms or initiating wrong immune responses or local accumulation of regulatory $\mathrm{T}$ cells that would oppose the effector T cell responses. Careful decoding of these biology events of tumor/host immune responses lead to immunotherapy approaches with a focus on blocking the negative regulatory pathways of $\mathrm{T}$ cell activity (check point blocking) [6], and engineering $\mathrm{T}$ cells and dendritic cells with tumor specific antigens to enhance anti-tumor responses.

\section{Blocking the Negative Regulation of T cell Activity}

Researchers have identified and targeted two major immune checkpoint mechanisms of T cell activity in the tumor microenvironment. These include cytotoxic $\mathrm{T}$ lymphocyte antigen-4 (CTLA-4) receptor based inactivation of $\mathrm{T}$ cells and programmed death (PD-1) pathway of $\mathrm{T}$ cell inhibition. Strategies that target both these mechanisms have received clinical validation and emerged as major advancements in cancer immunotherapy [6-8].

\section{Targeting CTLA-4 Receptor}

CTLA-4 is a negative regulator of immune activation and is expressed on activated T cells. CTLA- 4 on T cells interacts with B7 family of accessory molecules expressed on antigen presenting cells (APC), and prevents interaction of B7 of APC and CD28 of $\mathrm{T}$ cells [9-11]. Unlike B7 and CD28 interaction, the interaction of CTLA-4 with B7 is inhibitory in nature and blocks the further activation and expansion of $\mathrm{T}$ cells, and thus effectively control the over activation of $\mathrm{T}$ cells from causing chronic autoimmunity [11-14]. James Allison group in 1996 and 1999 reported that modification of endogenous $\mathrm{T}$ cell responses would result in potential anti-tumor effects in murine models. They used fully human IgG1 anti-CTLA-4 monoclonal antibodies to block CTLA4 and observed reduction in tumor growth in multiple murine tumor models $[15,16]$. This discovery has opened up the idea of targeting the negative regulatory pathways of $\mathrm{T}$ cells as a means to treat cancer.

In 1999, a biotechnology firm Medearex (later acquired in 2010 by Bristol-Mayer Squibb) has initiated clinical trials to test an anti-CTLA-4 antibody (Ipilimumab) in patients suffering with metastatic melanoma. In 2009 and 2010 they showed phase II clinical data with improved clinical activity with encouraging long term survival of previously treated advanced metastatic melanoma $[17,18]$. Phase III clinical trials with Ipilimumab reported a median survival rate of 10.1 months in unresectable stage III and IV melanoma patients treated with anti-CTLA-4 monoclonal antibody and glycoprotein 100 (gp100) vaccines relative to 6.1 month survival of patients receiving gp100 alone [19]. Also, patients treated with Ipilimumab after the standard decarbazine therapy showed an overall survival rate of 11.2 months compared to 9.1 months when received standard decarbazine therapy alone. Also, among the patients that received Ipilimumab and standard therapy, $\sim 21 \%$ were still alive after three years while it was $12 \%$ for patients that received standard therapy [20].

These are some of the first examples where a successful phase III data with improved survival rates is produced for the late stage metastatic melanoma. Ipilimumab is subsequently approved by FDA to treat metastatic melanoma patients for whom the first line of therapies have failed [21]. The improved clinical activity was found to be associated with increased tumor antigen specific $\mathrm{T}$ cells, increased pretreatment levels of tumor infiltrating lymphocytes and increased mutation load [22-27]. Infusion of CTLA-4 antibodies was also found to lead to some side effects such as colitis, dermatitis, demonstrating its role in peripheral tolerance. Many clinical trials are in progress to test if the anti CTLA-4 antibody therapy holds promise for other types of cancers such as prostate and renal cancers. Also, researchers are testing the hypothesis of further extending the survival rates by combining the immune modulating anti-CTLA-4 therapy with treatments that directly target tumor growth, angiogenesis (targeted therapies) [28].

Several other companies attempted clinical trials with IgG2 isotype of CTLA4 antibody, tremelimumab, for metastatic melanoma. Although phase I and II showed some response, phase III trials did not show any improved clinical anti-tumor activity and the trials were terminated [29]. However, investigations are currently underway using Tremelimumab either as monotherapy against metastatic mesothelioma or in combination with other immunotherapeutic drugs for multiple cancers, including nonsmall cell lung cancer, squamous cell carcinoma of the head and neck, bladder, pancreatic, gastric and liver cancers. Recent reports suggested that tremelimumab monotherapy did not demonstrate survival benefit for metastatic mesothelioma patients in phase IIb trials. However, the same group published a positive clinical outcome for tremelimumab in combination with durvalumab (PD-1 antibody) for non-small cell lung cancer in a phase Ib study [30].

\section{Targeting PD-1 pathway}

Programmed Death-1 (PD-1) is another inhibitory receptor expressed on the surface of $\mathrm{T}$ cells that are chronically active and exhausted, such as $\mathrm{T}$ cells in the tumor micro environment. PD-1 interacts with ligands PDL-1 and occasionally with PDL2 that are expressed on surface of antigen presenting cells or other immune cells or tumor itself. The PD-1/PDL-1 (or PDL2) Interactions render $T$ cell inactive and prevents further proliferation and cytokine production [31]. Unlike CTLA-4, PD-1 
does not interfere with co-stimulation of $\mathrm{T}$ cells, but interferes with signaling mediated by $\mathrm{T}$ cell antigen receptor [32]. It was found that PDL-1 is expressed on tumor after exposure to cytokines released from activated T cells indicating that PD-1/ PDL-1 pathway acts to protect the tumor cells from T cell attack [31]. So targeting these interactions using antibodies against PD-1 and PD L-1 to block this negative regulation pathway has gained momentum [33-39]. Two antibodies, nivolumab and pembrolizumab are approved recently in 2015 by FDA for the treatment of various cancers based on the clinical data that improved the overall survival $[40,41]$.

Pembrolizumab is IgG4 monoclonal anti-PD-1 antibody and was first approved anti-PD-1 antibody by FDA for the treatment of unresectable or metastatic melanomas after treatment with ipilimumab [41]. Pembrolizumab is also under clinical trials for the treatment of non-small cell lung cancer (NSCLC). Nivolumab is a fully human IgG4 monoclonal anti-PD-1 antibody, manufactured by Bristol-Myers Squibb and is found to be effective against advanced melanoma $(72.9 \%$ Survival rate after 1 year and 22\% after 3 years in Phase III trial [42], renal carcinoma and non-small cell lung cancer. Among several forms of immunotherapy, nivolumab appears to have high response rate. This may be because of wide distribution of PD-1 in various tissues (lymphoid, myeloid, dendritic, micro vascular endothelial cells) and organs (heart, lung, pancreas, muscle and placenta) suggesting that interactions of PD-1 with its ligand may be important in regulating $\mathrm{T}$ cells in peripheral tissues and inhibition of these with nivolumab may trigger a broader activation of $\mathrm{T}$ cells responses.

\section{CAR T- cell based adaptive Therapy}

Rosenberg et al. have developed chimeric antigen receptor (CAR) T cell based adaptive immunotherapy technology which involves genetic engineering of patient $\mathrm{T}$ cells to target tumor cell. CARs are developed in such a way that they will provide $\mathrm{T}$ cell with exquisite tumor antigen specific recognition, $\mathrm{T}$ cell activation and proliferation. The classic CARs have antigen recognition domain, a hinge domain, a transmembrane domain and an intracellular domain [43]. The antigen recognition domain is a single chain variable region of tumor antigen specific antibody and imparts specificity to recognize tumor cells [44]. The hinge region gives flexibility and transduces signals [45]. Transmembrane domain can be derived from variety of transmembrane receptors including CD4, CD10, CD28, and OX40 are found to influence the function of CAR T cells [46-48]. The intracellular domain is a signaling domain and is responsible for transmitting activation and co-stimulatory signals to $\mathrm{T}$ cells. The presence of a variety of co-stimulatory signaling molecules CD4, CD27, CD28, CD134, CD138, in signaling domain provide CAR $\mathrm{T}$ cells with functions such as $\mathrm{T}$ cell proliferation, cytokine production, and tumor lytic activities [49,50]. A variety of viral and non-viral platforms were developed to infuse CAR T cells into patients.
The major advantage of CAR T cell therapy is that it is not affected by tumor evading mechanisms to mount an immune response. It is independent of MHC dependent antigen presentation which generally limits endogenous $\mathrm{T}$ cell response when tumors down regulate $\mathrm{MHC}$ expression on their surface [51]. CARs can detect a variety of antigens expressed on tumor cell surface including proteins, lipids, carbohydrates for which antibodies can be generated [52]. CAR therapy can overcome the limitations of poor endogenous T cell immune response that are the result of cancer cell induced down regulation of the costimulatory molecules [53].

Although CAR $\mathrm{T}$ cell therapy is relatively a new immunotherapy approach, initial clinical results are eye-catching. Shannon et al. in 2014 reported that 27 (90\%) out of 30 acute lymphoblastic leukemia (ALL) patients that have undergone CAR T cell therapy targeting CD19 (CTL019) responded with a complete remission [54]. A high response is achieved even for patients with previously failed stem-cell transplantation (15 out of 30). Sustained remission was achieved even after 6 months with event free remission in and survival rate of $67 \%$ and overall survival rate of $78 \%$. CTL019 was also found to be persistent in the body at $68 \%$ even after 6 months indicating that these cells also show high in vivo proliferation.

This unprecedented early success of CAR T cell therapy raised enormous interest and now became the focus of many clinical trials. In addition to hematological malignancies such as acute lymphoblastic leukemia, clinicians also started attempting to test this approach in solid tumors. It is assumed that treating solid tumors with this approach is much more challenging than treating hematological malignancies given the local strong immune suppressive environment of tumors, shortage of specific antigens, and possible toxicity to normal tissues. Exploration of new targets, safe delivery mechanisms, optimized design of CAR vectors, and combination therapies are underway to treat solid tumors with CAR T cell therapy. Authors are redirected elsewhere for a more detailed description of challenges and strategies to treat solid tumors using CAR T cell therapy [55].

\section{Conclusion}

Until now chemotherapy, surgery, and radiation are the major treatment strategies for cancer. Now a fourth weapon namely cancer immunotherapy has been deployed. Recent advances in immunotherapy approaches such as checkpoint blockade and CAR $\mathrm{T}$ cell therapies are bringing new hope for patients with advanced disease. The attributes of target specificity, low toxicity and the ability to activate immune system holds a great promise for the immunotherapy. Blocking the CTLA-4, PD-1/ PDL-1 check points using their respective antibodies bring about a drastic shift in the way cancer therapy is operated because of the following reasons. First, these antibodies target the events involved in T cell activation rather than tumor itself. Second, the therapy is not used to activate immune cells to target tumors, 
but to relieve negative regulation path ways that block immune response.

In addition, to blocking the CTLA-4, PD-1/PDL-1, some other negative regulators LAG- 3 or TIM- 3 are also being actively pursued in clinical trials. Given CTLA- 4 and PD-1/PDL-1 are two distinct negative regulations, combination therapies targeting both pathways for possible synergistic effects are being explored in a large way for various cancers. CAR T cell immunotherapy also showed a great success in treating B cell malignancies and efforts are in full swing to apply the therapy to solid tumors as well. Apart from these approaches, many researchers are also attempting to identify patient specific biomarkers to develop effective patient specific and potent immunotherapeutic strategies. Despite these advances, immunotherapy still treats only a fraction of cancer patients and investigators are still searching for answers on why many can't benefit from immunotherapy. Nonetheless, a new concept to treat cancer patients with a great promise for future is brought into light.

\section{References}

1. Chen DS, Mellman I (2013) Oncology meets immunology: the cancerimmunity cycle. Immunity 39(1): 1-10.

2. Chen L, Flies DB (2013) Molecular mechanisms of T cell co-simulation and co-inhibition. Nature reviews Immunology 13(4): 227-242.

3. Muller WA (2016) Localized signals that regulate transendothelial migration. Current opinion in immunology 38: 24-29.

4. Slaney CY, Kershaw MH, Darcy PK (2014) Trafficking of T cells into tumors. Cancer Res 74(24): 7168-7174.

5. Koppolu V, Pack C, Selvaraj P (2015) Treatment of triple negative breast cancer using a tumor membrane based immunotherapy. Paper presented at: $7^{\text {th }}$ Asia-Pacific Biotech Congress, Beijing, China.

6. Sharma P, Allison JP (2015) The future of immune checkpoint therapy Science 348(6230): 56-61.

7. Shin DS, Ribas A (2015) The evolution of checkpoint blockade as a cancer therapy: what's here, what's next? Current opinion in immunology 33: 23-35.

8. Topalian SL, Drake CG, Pardoll DM (2015) Immune checkpoint blockade: a common denominator approach to cancer therapy. Cancer cell 27(4): 450-461.

9. Brunet JF, Denizot F, Luciani MF, Roux Dosseto, Suzan M, et al. (1987) A new member of the immunoglobulin superfamily-CTLA-4. Nature 328(6127): 267-270.

10. Linsley PS, Brady W, Grosmaire L, Aruffo A, Damle NK, et al. (1991) Binding of the B cell activation antigen B7 to CD28 costimulates T cell proliferation and interleukin 2 mRNA accumulation. J Exp Med 173(3): 721-730.

11. Linsley PS, Brady W, Urnes M, Grosmaire LS, Damle NK, et al. (1991) CTLA-4 is a second receptor for the B cell activation antigen B7. J Exp Med 174(3): 561-569.

12. Krummel MF, Allison JP (1995) CD28 and CTLA-4 have opposing effects on the response of T cells to stimulation. J Exp Med 182(2): 459-465.

13. Tivol EA, Borriello F, Schweitzer AN, Lynch WP, Bluestone JA, et al (1995) Loss of CTLA-4 leads to massive lymphoproliferation and fatal multiorgan tissue destruction, revealing a critical negative regulatory role of CTLA-4. Immunity 3(5): 541-547.
14. Waterhouse P, Penninger JM, Timms E, Wakeham A, Shahinian, et al. (1995) Lymphoproliferative disorders with early lethality in mice deficient in Ctla-4. Science 270(5238): 985-988.

15. Leach DR, Krummel MF, Allison JP (1996) Enhancement of antitumor immunity by CTLA-4 blockade. Science 271(5256): 1734-1736.

16. van Elsas A, Hurwitz AA, Allison JP (1999) Combination immunotherapy of B16 melanoma using anti-cytotoxic T lymphocyteassociated antigen 4 (CTLA-4) and granulocyte/macrophage colonystimulating factor (GM-CSF)-producing vaccines induces rejection of subcutaneous and metastatic tumors accompanied by autoimmune depigmentation. J Exp Med 190(3): 355-366.

17. Camacho LH, Antonia S, Sosman J, Kirkwood JM, Gajewski TF, et al (2009) Phase I/II trial of tremelimumab in patients with metastatic melanoma. J clin oncol 27(7): 1075-1081.

18. O Day SJ, Maio M, Chiarion-Sileni V, Gajewski TF, Pehamberger H, et al. (2010) Efficacy and safety of ipilimumab monotherapy in patients with pretreated advanced melanoma: a multicenter single-arm phase II study. Ann oncol 21(8): 1712-1717.

19. Hodi FS, O Day SJ, McDermott DF, Weber RW, Sosman JA, et al. (2010) Improved survival with ipilimumab in patients with metastatic melanoma. N Engl J Med 363(8): 711-723.

20. Robert C, Thomas L, Bondarenko I, O Day S, Weber J, et al. (2011) Ipilimumab plus dacarbazine for previously untreated metastatic melanoma. N Engl J Med 364(26): 2517-2526.

21. Koppolu V, Vasigala V (2016) CTLA-4 antibodies in cancer immunotherapy. MOJ Immunol 3(3): 00092.

22. Snyder A, Makarov V, Merghoub T, Jianda Yuan, Jesse M, et al. (2014) Genetic basis for clinical response to CTLA-4 blockade in melanoma. The New England journal of medicine 371(23): 2189-2199.

23. Van Allen EM, Miao D, Schilling B, Shukla SA, Blank C, et al. (2015) Genomic correlates of response to CTLA-4 blockade in metastatic melanoma. Science 350(6257): 207-211.

24. Yuan J, Adamow M, Ginsberg BA, Rasalan TS, Ritter E, et al. (2011) Integrated NY-ESO-1 antibody and CD8+ T-cell responses correlate with clinical benefit in advanced melanoma patients treated with ipilimumab. Proc Natl Acad Sci USA 108(40): 16723-16728.

25. Ji RR, Chasalow SD, Wang L, Hamid O, Schmidt H, et al. (2012) An immune-active tumor microenvironment favors clinical response to ipilimumab. Cancer immunol immunother 61(7): 1019-1031.

26. Skredenske JM, Koppolu V, Kolin A, Deng J, kettle B, et al. (2013) Identification of a small-molecule inhibitor of bacterial AraC family activators. J Biomol screen18(5): 588-598.

27. Koppolu V, Osaka I, Skredenske JM, Kettle B, Hefty PS, et al. (2013) Small-molecule inhibitor of the Shigella flexneri master virulence regulator VirF. Infect immun 81(11): 4220-4231.

28. Hughes PE, Caenepeel S, Wu LC (2016) Targeted Therapy and Checkpoint Immunotherapy Combinations for the Treatment of Cancer. Trends immunol 37(7): 462-476.

29. Ribas A, Kefford R, Marshall MA, Punt CJ, Haanen JB, et al. (2013) Phase III randomized clinical trial comparing tremelimumab with standardof-care chemotherapy in patients with advanced melanoma. J clin oncol 31(5): 616-622.

30. Antonia S, Goldberg SB, Balmanoukian A, Chaft JE, Sanborn RE, et al. (2016) Safety and antitumor activity of durvalumab plus tremelimumab in non-small cell lung cancer: a multicentre, phase $1 \mathrm{~b}$ study. Lancet Oncol 17(3): 299-308.

31. Dong H, Strome SE, Salomao DR, Tamura H, Hirano F, et al. (2002) Tumor-associated B7-H1 promotes T-cell apoptosis: a potential mechanism of immune evasion. Nat Med 8(8): 793-800. 
32. Greenwald RJ, Freeman GJ, Sharpe AH (2005) The B7 family revisited. Annu Rev Immunol 23: 515-548.

33. Koppolu V, Vasigala VK (2016) Role of Escherichia coli in Biofuel Production. Microbiol Insights 9: 29-35.

34. Skredenske JM, Koppolu V, Kolin A, Deng J, Kettle B, et al. (2013) Identification of a small-molecule inhibitor of bacterial AraC family activators. J Biomol Screen 18(5): 588-598.

35. Topalian SL, Hodi FS, Brahmer JR, Smith DC, Gettinger SN, et al. (2012) Safety, activity, and immune correlates of anti-PD-1 antibody in cancer. N Engl J Med 366(26): 2443-2454.

36. Thompson RH, Gillett MD, Cheville JC, Lohse CM, Dong H, et al. (2004) Costimulatory B7-H1 in renal cell carcinoma patients: Indicator of tumor aggressiveness and potential therapeutic target. Proc Natl Acad Sci USA 101(49): 17174-17179.

37. Lipson EJ, Sharfman WH, Drake CG, Wollner I, Taube JM, et al. (2013) Durable cancer regression off-treatment and effective reinduction therapy with an anti-PD-1 antibody. Clin Cancer Res 19(2): 462-468.

38. Koppolu V, Osaka I, Skredenske JM, Kettle B, Hefty PS, et al. (2013) Small-molecule inhibitor of the Shigella flexneri master virulence regulator VirF. Infect Immun 81(11): 4220-4231.

39. Koppolu V (2013) Molecular Mechanisms and Inhibition of Transcription Activation by Bacterial AraC Family Activator Proteins. University of Kansas, USA.

40. Gunturi A, McDermott DF (2015) Nivolumab for the treatment of cancer. Expert opinion on investigational drugs 24(2): 253-260.

41. Khoja L, Butler MO, Kang SP, Ebbinghaus S, Joshua AM (2015) Pembrolizumab. Journal for immunotherapy of cancer 3: 36.

42. Robert C, Long GV, Brady B, caroline D, Michele M, et al. (2015) Nivolumab in previously untreated melanoma without BRAF mutation. N Engl J Med 372(4): 320-330.

43. Whilding LM, Maher J (2015) CAR T-cell immunotherapy: The path from the by-road to the freeway? Mol oncol 9(10): 1994-2018.

44. Shi H, Sun M, Liu L, Wang Z (2014) Chimeric antigen receptor for adoptive immunotherapy of cancer: latest research and future prospects. Mol cancer 13: 219.

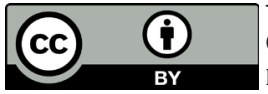

This work is licensed under Creative

Commons Attribution 4.0 License

DOI: 10.19080/CTOIJ.2017.05.555661
45. Hudecek M, Sommermeyer D, Kosasih PL, Liu L, Rader C, et al. (2015) The nonsignaling extracellular spacer domain of chimeric antigen receptors is decisive for in vivo antitumor activity. Cancer Immunol Res 3(2): 125-135.

46. Dotti G, Gottschalk S, Savoldo B, Brenner MK (2014) Design and development of therapies using chimeric antigen receptor-expressing T cells. Immunol Rev 257(1): 107-126.

47. Harris DT, Kranz DM (2016) Adoptive T Cell Therapies: A Comparison of $\mathrm{T}$ Cell Receptors and Chimeric Antigen Receptors. Trends in pharmacological sciences 37(3): 220-230.

48. Mulagapati S, Koppolu V, Raju TS (2017) Decoding of O-Linked Glycosylation by Mass Spectrometry. Biochemistry 56(9): 1218-1226.

49.Zhong XS, Matsushita M, Plotkin J, Riviere I, Sadelain M (2010) Chimeric antigen receptors combining 4-1BB and CD28 signaling domains augment PI3kinase/AKT/Bcl-XL activation and CD8+ T cellmediated tumor eradication. Mol Ther 18(2): 413-420.

50. Long AH, Haso WM, Shern JF, Murgai M, Smith JP, et al. (2015) 4-1BB costimulation ameliorates $\mathrm{T}$ cell exhaustion induced by tonic signaling of chimeric antigen receptors. Nat Med 21(6): 581-590.

51. Catalan E, Charni S, Jaime P, Aquilo JI, Naval J, et al. (2015) MHC-I modulation due to changes in tumor cell metabolism regulates tumor sensitivity to CTL and NK cells. Oncoimmunology 4(1): e985924.

52. Hillerdal V, Essand M (2015) Chimeric antigen receptor-engineered T cells for the treatment of metastatic prostate cancer. BioDrugs 29(2): 75-89.

53. Duong CP, Yong CS, Kershaw MH, Slaney CY, Darcy PK (2015) Cancer immunotherapy utilizing gene-modified T cells: From the bench to the clinic. Mol Immunol 67(2): 46-57.

54. Maude SL, Frey N, Shaw PA, Richard A, David MB, et al. (2014) Chimeric antigen receptor $\mathrm{T}$ cells for sustained remissions in leukemia. $\mathrm{N} \mathrm{Engl} \mathrm{J}$ Med 371(16): 1507-1517.

55. Zhang H, Ye ZL, Yuan ZG, Luo ZQ Jin HJ, et al. (2016) New Strategies for the Treatment of Solid Tumors with CAR-T Cells. International Journal of Biological sciences 12(6): 718-729.

\section{Your next submission with Juniper Publishers will reach you the below assets}

- Quality Editorial service

- Swift Peer Review

- Reprints availability

- E-prints Service

- Manuscript Podcast for convenient understanding

- Global attainment for your research

- Manuscript accessibility in different formats

( Pdf, E-pub, Full Text, Audio)

- Unceasing customer service

Track the below URL for one-step submission https://juniperpublishers.com/online-submission.php 